handle than the electron beam processing, because the former requires no evacuation, neither continuous processing nor continuous output of high energy density is possible. The laser beam is, however, better than the electron beam in power efficiency, as estimated by the amount of material evaporated.

\section{Rubberized Surfacing Materials for Roads}

IT has long been known that the rheological properties of tar and bitumen are appreciably altered when small proportions of natural rubber are added. Extensive investigations at the Road Research Laboratory into the properties of rubberized binders have boen carried out in co-operation with the Natural Rubber Producers' Resoarch Association and the Natural Rubber Bureau, and a series of full-scale road experiments have been initiated during the past ten years at various places in Britain. The results of these experiments up to May 1963 are now available in Road Research Laboratory Technical Paper No. 71, by P. D. Thompson (Full-Scale Road Experiments Using Rubberized Surfacing Materials, 1953-1963. Pp. iv +24. London: H.M.S.O., 1964. 3s. net). The types of 'black top' surfacing concerned in these experiments are mastic asphalt, rolled asphalt, bitumen macadam, dense tar surfacing, tar surface dressing, and bitumen surface dressing. A summary of the essential results of these road experiments may be stated as follows: (1) Addition of rubber to mastic asphalt prevents or markedly reduces the cracking which occurs when a bituminous surfacing is laid over joints or cracks in a concrete base; (2) addition of 10 per cent of rubber to the binder of rolled asphalt reduces the number and severity of cracks in this surfacing material when laid over joints and cracks in a concrete base; (3) a substantial increase in life is obtained when 4 per cent of powdered rubber is added to the binder of bitumen macadam; (4) "a limited full-scale experiment has suggested that the life of dense tar surfacing may possibly be increased by the addition of rubber powder to the binder"; (5) "in one surface-dressing experiment, a commercially available rubber-tar showed no improvement over normal tar. Interim results of a second experiment suggest that some advantage may be gained by the use of a graft rubber-tar in the tar surface dressing"; (6) "a considerable reduction in the tendency of bitumen surface dressings to 'fat up' in hot weather under heavy traffic has been shown when rubber has been blended with the binder". In so far as the results of these experiments may be indicative at this stage, it would appear that the greatest advantages of rubberized binders are realized when asphaltic bitumen is the major adhesive. The experiment with dense tar surfacing seems inconclusive. In the case of tar surface dressing, a second full-scale experiment has recently been started further to assess the possibilities when graft-rubber is added to the binder.

\section{Bibliography of Cold Weather Concreting}

THe subject of the many and varied technical problems raised in concrete construction during the winter months has for years past been one of major concern in the building and engineering industries; few indeed will readily forget the disastrous conditions occasioned by the severity and duration of the freezing temperatures in Britain in the winter of 1962-63. The subject, however, is one still receiving considerable attention, not only from cement and concrete technologists, but also in its economic and practical significance; this interest is international, at least in temperate climates. The Cement and Concrete Association, London, has recently produced a bibliography covering articles, papers and books dealing with the subject of cold weather concreting practice, the use of ready-mixed concrete under these conditions, and the heating of aggregates (Bibliography of Cold Weather Concreting. Pp. 29. (Ref. Ch.48. 10/64.) Pp. 29.
London: Cement and Concrete Association, 1964. 5s.) This useful document lists nearly 400 references to this subject in international literature, ranging in time from early 1964 back to 1912. This in itself is sufficient evidence of the undiminished importance of the problem and, perhaps, of the still formidable technical obstacles to be overcome before a final and universally acceptable solution is reached (if ever). To those studying cold weather concreting in all its phases, likewise all concerned with the design and construction of buildings, bridges, roads, runways, involving particularly in situ concreting under aretic conditions, this bibliography is bound to prove of great value.

\section{Respiratory Function and Failure}

NoRmal respiratory function requires adequate ventilation of alveoli, proper exchange of oxygen and carbon dioxide between air and blood by diffusion, and adequate transport of blood to and from the lungs via the pulmonary circulation. Respiratory failure can occur through dysfunction of any one of these three processes or of two or more in combination. To understand why s uch failure has occurred and to treat it correctly, measurements of each physiological process may be required. Accurate and easily performed quantitative tests are available and may be used when necessary to supplement information obtained by radiography, bronchoscopy and routine laboratory procedures. Pulmonary function and the tests for respiratory failure are described in the Central African Journal of Medicine (10, No. 10; October 1964) by Dr. A. J. P. Graham, who has also advocated their use at the bedside or in the consulting room. A later article will be devoted to describing the clinical picture, and discussing the management of respiratory failure in the acute and chronic stages.

\section{The Ornamental Sea-toad}

A PHOTOGRAPH showing the carapace of the ornamental sea-toad, Schizophrys dama, a spider-crab from Broome, north-western Australia, appears in Australian Natural History (14, No. 11). Only one other illustration, now difficult to obtain, of this distinctive crab has appeared since the first hand-coloured plate was published in Berlin in 1804 by the German naturalist, Joann Friedrich Herbst, with his original deseription of the animal. $S$. dama is found inter-tidally and in shallow water from the Albany area of south-western Australia, through western and northern Australia to northern Queensland, and, during life, the carapace is often partly concealed under a cover of sponge and other marine growths. Two thorn-like spines project laterally from each of the elongate rostral horns at the front of the carapace. This feature serves to distinguish $S$. dama from the closely allied red sea-toad, Schizophrys aspera, which has only one lateral spine to each rostral horn. S. aspera is found in a similar habitat through southern, western and northern Australia and along the entire Queensland coast and Barrier Reef area. It has not yet been recorded from New South Wales or Victoria.

\section{University News:}

Bangor

DR. W. L. WiLcock, at present reader in instrument technology at the Imperial College of Science and Technology, London, has been appointed to the recently instituted additional chair in the Department of Physics, with effect from October 1.

Liverpool

Dr. A. Young, at present reader in numerical analysis and director of the Computer Laboratory, has been appointed to the newly established chair of numerical analysis. Dr. N. M. Hancox, at present reader in histology, has been appointed to the newly established chair of histology. The following lecturers have also been appointed: Dr. J. V. Allaby, Dr. K. Bearpark, Mr. L. J. 